\title{
AUDIT OF INTRA-UTERINE INSEMINATION WITH PARTNER'S SPERM
}

\author{
L Anuradha, Specialist Registrar; D E P Shapland, Consultant; \\ Obstetrics \& Gynaecology; B A Teague, Manager; \\ H M Pratt, Assistant; Clinical Audit Furness General Hospital
}

\section{INTRODUCTION}

Intra-uterine insemination (IUI) refers to the direct transfer of sperm to the intra-uterine cavity. It has been used for a variety of indications for greatly varying pregnancy rates, including infertility due to male factor, cervical hostility or antisperm antibodies and idiopathic infertility.

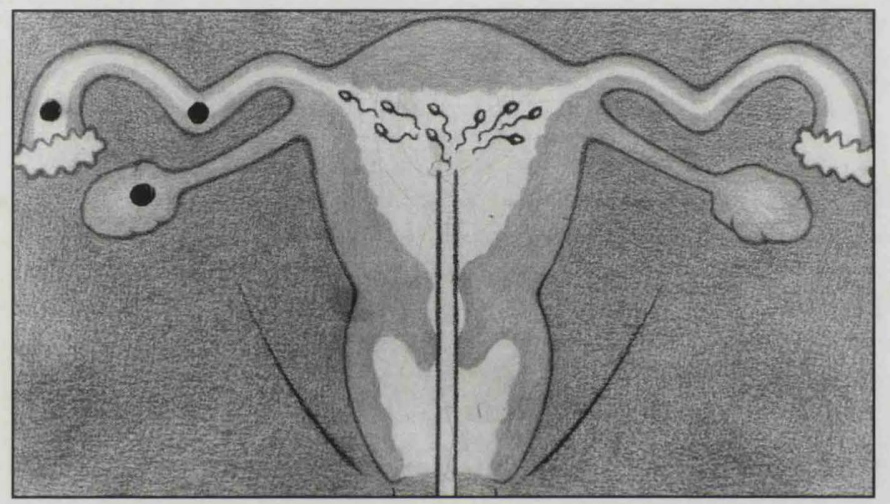

Figure 1 Direct transfer of sperm to the uterine cavity

The most frequently reported indication for treatment with IUI is infertility due to male factor including low sperm counts and poor sperm motility. Most authors note a poor success rate with male factor infertility; this is not however included in the selection criteria in our unit. Patients treated with IUI for infertility associated with cervical factor achieved a higher pregnancy rate, as did patients with unexplained infertility. Empirical treatment of unexplained infertility with superovulation combined with IUI was proposed by Sher et al in 1984 . $^{(1)}$

Underlying unexplained infertility, including mild endometriosis and abnormalities associated with ovulation, may be subtle causes of subfertility, hence the rationale for using controlled ovarian hyperstimulation with IUI. This is achieved with gonadotrophin injections without prior pituitary desensitisation. Treatment usually starts on day 2 of the cycle and USS monitoring commences on day 9. Ovarian stimulation is continued until there are two to three follicles of $16 \mathrm{~mm}$ or more. This should boost the fertility.

Sperm can be prepared in a number of ways. It can be achieved by albumin column technique, or a discontinuous percoll gradient, or a swim-up technique. In this unit we use the swim-up technique. Sperm washing is achieved by diluting a sample of liquefied sperm in culture medium followed by centrifugation and resuspension in the medium, thereby removing seminal plasma but leaving bacteria and motile spermatozoa in the preparation. The sample is enhanced further if the wash is repeated and the sperm then left to swim up to the surface for thirty to sixty minutes.
IUI is performed thirty to forty hours after BhCG injection. 0.1 to $1 \mathrm{ml}$ of prepared sperm is placed in the uterine cavity using a fine cannula.

All patients are fully investigated and those who fulfil the criteria are enrolled for controlled ovarian hyperstimulation and IUI with partner's sperm. Each couple is offered three treatment cycles.

\section{AIM OF THE AUDIT}

The aim was to determine the effectiveness of IUI treatment with controlled ovarian hyperstimulation $(\mathrm{COH})$ in a district general hospital.

\section{STANDARDS}

Couples who meet the following criteria are eligible for recruitment to the IUI programme at Furness General Hospital:-

- Unexplained infertility cervical factor minimal endometriosis anovulatory - where simple ovulation induction failed

- age of female $\leq 40$ years

- number of follicles 2-3

- number of cycles 3 maximum

- sperm quality $1 \times 10^{6} \quad$ in practice sperm $\geq 80 \%$ motile $\}$ prepartion

\section{METHODOLOGY}

The infertility clinic diaries were used as the data source to identify patients who underwent infertility treatment in the form of IUI during a two-year period (January 1996 to December 1997). Patients who were still receiving treatment were excluded from the populatioin sample. The medical casenotes incorporating the gynaecological notes and relevant maternity notes were extracted. A proforma was designed for retrospective data collection.

\section{RESULTS}

Forty couples met the criteria for selection during the twoyear audit period. The majority of females (33) were in the $30-39$ age group (median age 33 years). $78 \%$ had primary infertility (median duration five years). The sperm count was normal in $78 \%$ of males (31) and subnormal in $15 \%$ (6). No information was recorded for three males $(7 \%)$. There was an 
overlap in the indications for referral. Unexplained infertility accounted for $47.5 \%$ (Table 1 ).

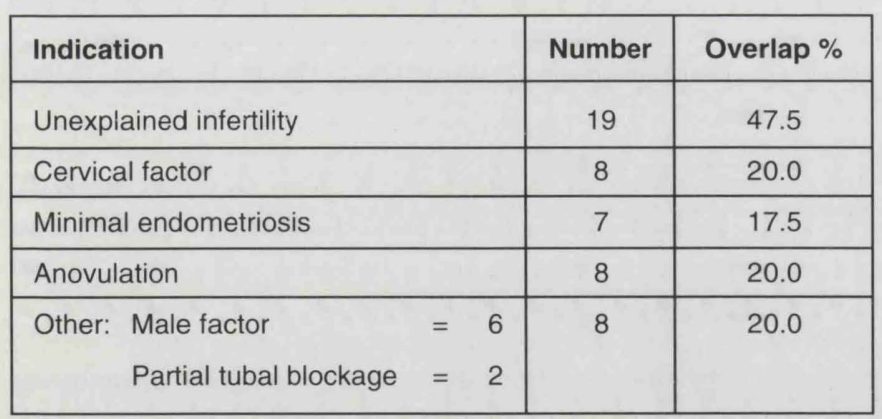

Table 1 Overlap of indications for referral. $n=40$

Seven couples (17.5\%) withdrew from the programme prior to treatment, mainly because of personal problems or the programme was too stressful. A request for donor insemination was made by one couple.

Of the 33 couples who continued on the programme, 25 (76\%) met the criteria for selection. A subnormal sperm count was recorded for six males $(18 \%)$. Two females $(6 \%)$ had a partial tubal blockage. One abandoned the programme after receiving two cycles of treatment and the other became pregnant by natural conception one month after the first cycle. The duration of infertility for the 33 couples ranged from 1-13 years (median four years). All patients received $\mathrm{COH}$. Overall there was a total of 64 treatment cycles (Table 2).

\begin{tabular}{|c|c|c|}
\hline Number of cycles & Number of patients & Percentage \\
\hline 1 & 14 & $42.5 \%$ \\
\hline 2 & 7 & $21.0 \%$ \\
\hline 3 & 12 & $36.5 \%$ \\
\hline
\end{tabular}

Table 2 Treatment cycles per patient. $n=33$

Thirty-five treatment cycles $(55 \%)$ failed to produce the required number of eggs. Three patients produced more than three follicles. Two women continued on the programme and later produced two follicles at the next treatment cycle and both later referred for IVF. Both patients failed to conceive at the third treatment cycle and were later referred for IVF. One patient who produced six follicles after the first treatment cycle also had Raynaud's and scleroderma. It was thought that a pregnancy might aggravate her pre-existing medical condition. She was withdrawn from the programme and not referred for IVF.
There were six patients who conceived following treatment. One patient had a natural conception one month after her first treatment cycle. Thus the pregnancy rate following $\mathrm{COH}$ was $8 \%$ per cycle. It was noted that the five couples had all met the programme recruitment criteria. Overall they received a total of nine treatment cycles before conception (Table 3).

A fullterm pregnancy was achieved by four patients (Table 4). The fifth pregnancy was an ectopic gestation which proceeded to a linear salpingostomy.

\begin{tabular}{|l|c|c|}
\hline pregnancy rate per cycle & $5 / 64$ & $8 \%$ \\
\hline overall pregnancy rate & $5 / 33$ & $15 \%$ \\
\hline live birth rate & $4 / 33$ & $12 \%$ \\
\hline
\end{tabular}

Table 4 Pregnancy rate. $n=33$

Twenty-seven patients ( $82 \%$ ) failed to conceive following treatment (Table 5).

\begin{tabular}{|l|c|}
\hline Outcome & Number of patients \\
\hline referred for IVF & 18 \\
\hline referred for donor insemination & 1 \\
\hline referred to urologist & 1 \\
\hline abandoned treatment & 7 \\
\hline
\end{tabular}

Table 5 Outcome of patient who failed to conceive. $n=27$

No further contact was made by two of the seven patients who abandoned treatment. Two patients were withdrawn from the programme because of ovarian hyperstimulation. Another was withdrawn because of a poor response and was advised to lose weight. One patient abandoned the programme because of a mental breakdown. The seventh patient had three treatment cycles but failed to conceive. There was no documentation as to whether this patient was referred for IVF.

\section{ADHERENCE TO STANDARDS}

\section{Standard 1}

25 of the 33 patients met the criteria for selection $=76 \%$

\section{Standard 2}

33 females were within the age group $\leq 40$ years $=100 \%$

Standard 3

29 of the 64 treatment cycles produced $2-3$ follicles $=45 \%$

\section{Standard 4}

33 patients were offered a maximum of three treatment cycles

$=100 \%$

Standard 5

27 males had a normal sperm count

\begin{tabular}{|c|c|c|c|c|c|c|}
\hline $\begin{array}{c}\text { Female } \\
\text { age }\end{array}$ & $\begin{array}{c}\text { Duration of } \\
\text { infertility }\end{array}$ & $\begin{array}{c}\text { Indication for } \\
\text { referral }\end{array}$ & $\begin{array}{c}\text { Conception } \\
\text { cycle }\end{array}$ & $\begin{array}{c}\text { Number } \\
\text { of follicles }\end{array}$ & $\begin{array}{c}\text { Treatment } \\
\text { to conception }\end{array}$ & $\begin{array}{c}\text { Sperm } \\
\text { Count }\end{array}$ \\
\hline 31 & 1 year & unexplained infertility & first & 2 & 1 year & normal \\
\hline 32 & 1 year & unexplained infertility & third & 1 & 1 year & normal \\
\hline 33 & 3 years & anovulation & second & 3 & 1 year & normal \\
\hline 34 & 6 years & unexplained infertility & second & 2 & 1.5 years & normal \\
\hline 35 & 8 years & minimal endometriosis & first & 2 & 1 year & normal \\
\hline
\end{tabular}

Table 3 Characterisation of patients who conceived. $n=5$ 


\section{CONCLUSION}

The audit revealed an overall pregnancy rate of $15 \%$ and live birth rate of $12 \%$, which compares favourably with published research findings. Three of the five standards, however, were not achieved. The five couples who became pregnant all met the criteria for selection and produced two to three follicles per treatment cycle. Whilst it appears from the data that the number of follicles per treatment cycle is important, all five standards appear to be equally important in order to achieve a successful outcome. Strict adherence to the criteria for selection will improve the success rate.

The six males with a subnormal sperm count were recruited to the programme prior to 1996 when this factor was included in the selection criteria. Subsequently five of the six couples were referred for IVF and the sixth was referred for donor insemination. Similarly, tubal blockage is not an indication for IUI and two females with partial tubal blockage were recruited for treatment. If these eight patients had not been recruited to the programme the pregnancy rate would have been $20 \%$. This highlights the imporatance of the selection criteria.

\section{RECOMMENDATIONS}

- Strict adherence to the eligibility criteria will further improve the success rate

- treatment cycles which produce fewer than two follicles should be abandoned

- treatment protocols for $\mathrm{COH}$ should be revised

- reducing the female age limit to 36 years would lead to earlier IVF referral and thereby increase the chance of success in that treatment

- consideration should be given to pre-treatment of sperm and transuterine intra-tubal insemination

\section{REFERENCES}

1 Sher G, Knutzen VK, Stratton CJ, et al Invitrosperm capacitation and transcervical intrauterine insemination for the treament of refactory infertility: Phase 1. Fertil Steril 1984; 41: 260-264.

2 Arcaini L, Bianchi S, Baglioni A, Marchini M, Tozzi L, Fedel L Superovulation and intrauterine insemination vs superovulation alone in the treatment of unexplained infertlity J Reprod Med 1996; 41(8): 614-18

3 Ford WCL, Mathur RS, Hull MGR Intrauterine insemination: is it an effective treatment for male factor infertility? Baillière's Clin Obs and Gyn 1997; 11(4): 691709

4 Vollenhoven B, Selub M, Davidson O, Lefkow H, Serepa N, Hung TT Treating infertility: controlled ovarian hyperstimulation using human menopausal gonadotropin in combination with intrauterine inseminatin J Repro Med 1996; 41 (9): 658-64

5 Allen NC, Herber CM, Maxson WS, Rogers BJ, Diamond MP, Wentz AC Intrauterine insemination: a critical review Fertil and Steril 1985; 44(5): 569-684

6 Dobson, Haney Controlled ovarian hyperstimulation and IUI Fertil and Steril 1991; 55 (3): 457-67 